\title{
0 impacto da criação da Funpresp sobre os benefícios previdenciários dos servidores públicos federais
}

\author{
Danilo Diogenes Rodrigues \\ EY Serviços Atuariais \\ São Paulo / SP - Brasil \\ Luís Eduardo Afonso \\ Universidade de São Paulo / Faculdade de Economia, Administração e Contabilidade, \\ Departamento de Contabilidade e Atuária \\ São Paulo / SP - Brasil
}

\begin{abstract}
O objetivo deste trabalho é quantificar os impactos da criação da Funpresp em 2012, tendo como foco os funcionários públicos federais ativos. Com o emprego de técnicas de matemática atuarial, por meio do cálculo de anuidades calcula-se a diferença entre o benefício de aposentadoria que os servidores teriam no antigo e no novo regime previdenciário. A mudança é desfavorável para todos os servidores e servidoras de diferentes idades e níveis de remuneração, com perdas de cerca de $15 \%$. Adicionalmente, são analisadas as condições que deveriam ser verificadas para que não houvesse prejuízos aos servidores. Somente deixaria de haver redução de benefícios nas condições altamente improváveis de uma taxa de juros real superior a $9 \%$ ou se os atuais servidores passassem a contribuir com $47 \%$ de seu salário para a Funpresp. Esses resultados ilustram a necessidade de medidas para aumentar o nível informacional dos servidores para que eles possam entender adequadamente os impactos dessa medida.
\end{abstract}

Palavras-chave: previdência social; Funpresp; servidores públicos; reforma da previdência.

El impacto de la creación de Funpresp sobre los beneficios de pensiones de los funcionarios federales

El objetivo de este estudio es cuantificar el impacto de la creación de Funpresp en 2012, centrándose en los empleados federales activos. Con el uso de técnicas matemáticas actuariales a través del cálculo de anualidades se calcula la diferencia entre el beneficio de jubilación que los servidores tendrían en el viejo y en el nuevo régimen de pensiones. El cambio es desfavorable para todos los servidores de diferentes edades y niveles de remuneración, con pérdidas de alrededor del 15\%. Además se analizan

DOI: http://dx.doi.org/10.1590/0034-7612141592

Artigo recebido em 12 out. 2014 e aceito em 10 jun. 2015.

(c) (1) 
las condiciones que deben revisarse para que no hubiera daños a los servidores. Sólo dejará de ser una reducción de los beneficios en circunstancias muy poco comunes de una tasa de interés real de $9 \%$ y los servidores actuales para empezar a contribuir el $47 \%$ de su salario para Funpresp. Estos resultados ilustran la necesidad de tomar medidas para aumentar el nivel de información de los servidores para que puedan comprender adecuadamente los impactos de esta medida.

Palabras-chave: seguridad social; Funpresp; funcionarios; reforma de las pensiones.

The impact of the creation of Funpresp on the pension benefits of federal civil servants The goal of this study is to quantify the impacts of the creation of Funpresp in 2012, focusing on the active federal civil servants. Using techniques of actuarial mathematics, through the calculation of annuities, we calculate the difference between the retirement benefits in the old and in the new pension regime. The change is unfavorable for all servers of different ages and income levels, with losses of about $15 \%$. Additionally, we analyzed the set of conditions that should be verified so that any worker would be affected by the changes. Only in the highly unlikely circumstances of a real interest rate above $9 \%$ or a contribution rate of $47 \%$ of the income for Funpresp that would be no reduction in the benefits. These results illustrate the need for action to increase the informational level of civil servants in order they can understand correctly the impacts of the creation of Funpresp.

KEYWORDs: social security; Funpresp; civil servants; pension reform.

\section{Introdução}

No dia 30 de abril de 2012, no primeiro mandato de Dilma Rousseff, a Lei no 12.618 instituiu o regime de previdência complementar para os servidores públicos federais e autorizou a criação das Fundações de Previdência Complementar (Funpresp) para os servidores dos três poderes da União. Esse importante ato jurídico pode ser entendido como uma continuação das reformas previdenciárias executadas nos governos Lula e FHC. Torna o sistema previdenciário brasileiro mais igualitário, uma vez que aproxima o regime previdenciário dos servidores públicos federais do regime dos trabalhadores do setor privado. Essa é uma tendência verificada em diversos países (Pallares-Miralles et al., 2012).

Nas regras vigentes antes da mudança, o servidor público tinha a garantia de receber um benefício de valor proporcional aos maiores salários. Com a criação da Funpresp, o teto de benefícios do Regime Próprio da Previdência Social (RPPS) da União passa a ser igual ao do Regime Geral da Previdência Social (RGPS). Ou seja, independentemente da remuneração na fase ativa, os servidores federais terão seu benefício limitado a $R \$ 4.159,00$ (valor vigente em 2013). Entretanto, poderão contribuir para um plano de previdência complementar, a Funpresp, para complementar sua aposentadoria. A lei é válida para os servidores que entrarem no serviço público após o início do funcionamento da Funpresp. No entanto, aqueles que já estiverem no serviço público poderão optar entre permanecer no atual regime, ou migrar para o novo, no prazo de 24 meses a partir da criação da entidade de previdência. Os servidores que optarem pela migração contarão com um incentivo, na forma de 
um benefício especial.

Com base neste quadro, o objetivo do trabalho é quantificar como os servidores públicos serão afetados pela criação da Funpresp. Para isso são calculados os benefícios previdenciários no antigo regime e no novo regime. Dessa maneira, deseja-se responder as seguintes perguntas: quais os impactos para o servidor que opta por deixar o antigo regime do RPPS e aderir à Funpresp? Quais condições teriam de ser verificadas para que o servidor não tivesse perdas?

Este trabalho está dividido em mais cinco seções, além desta introdução. Na próxima seção é feita a fundamentação teórica. A seção três apresenta os procedimentos metodológicos adotados e a seção quatro apresenta os resultados obtidos. Na seção cinco são feitas extensões dos resultados iniciais. Por fim, a sexta seção apresenta as conclusões do artigo.

\section{Fundamentos e breve revisão da literatura empírica}

\subsection{Base teórica}

Sistemas previdenciários têm como objetivo primário a suavização do consumo quando da passagem do trabalhador do período laboral para a inatividade, devido à redução no fluxo de renda do trabalho (Feldstein e Liebman, 2002). Adicionalmente, dado que os indivíduos enfrentam um grande conjunto de incertezas ao longo de sua vida, outras funções como reduzir a pobreza, atender a princípios distributivos e funcionar como um mecanismo de seguro contra eventos adversos podem ser desempenhadas pela previdência social (Barr e Diamond, 2006).

A existência de sistemas previdenciários pode ser justificada por vários motivos. Mulligan e Sala-I-Martin (1999a, 1999b), em sua extensa revisão, dividem esses motivos em duas categorias. A primeira fundamenta-se nos princípios da economia política, na qual se entende que a existência da previdência é fruto de uma batalha política intergeracional por recursos, na qual o resultado é a "vitória" dos idosos, sendo a recompensa a criação de mecanismos previdenciários. A segunda categoria tem como base um argumento ligado à eficiência. Nesse caso, a existência da previdência se justificaria pela redução ou correção de falhas de mercado como miopia, seleção adversa e externalidades do capital humano, entre outros.

O Brasil não é o único país a ter um regime exclusivo para servidores públicos (Palacios e Whitehouse, 2006). Em vários países como os EUA (Mitchell et al., 2001) e Holanda (Kerkhoff, 2009) a criação de regimes para funcionários públicos antecede a criação de sistemas previdenciários para trabalhadores do setor privado. Como apontam Hustead e Hustead (2001), a existência de regimes diferenciados (com benefícios mais elevados) pode ser justificada pelo menor rendimento e pelo fato de algumas carreiras no serviço público serem bastante específicas. Esse fato geraria certa rigidez no mercado de trabalho, impedindo transições entre diferentes ocupações. No entanto, como no caso brasileiro, outros países também 
passaram por reformas visando unificar seus regimes previdenciários, ou buscando alternativas para redução de despesas públicas. Porém, tais mudanças enfrentam grande resistência dos grupos afetados (Barr e Diamond, 2008).

A criação da Funpresp pode ser entendida em um contexto mais amplo, apontado por Petrichev e Thorp (2008) de aumento da parcela dos regimes de capitalização, de contribuição definida, em relação aos regimes de repartição, de benefício definido, na composição do benefício previdenciário. Diversos países da América Latina fizeram reformas dessa natureza na década de 1990 (Mesa-Lago e Müller, 2002). Tais alterações fazem com que uma proporção maior do risco previdenciário seja arcada pelo trabalhador, ao invés da instituição, como ocorre tipicamente em regimes de benefício definido (Novy-Marx e Rauh, 2014). Dessa maneira, é digno de nota que a criação da Funpresp encontra respaldo no conceito dos sistemas previdenciários multipilares. Nesse caso, cada pilar tem uma função, provendo proteção em relação a riscos de baixa correlação entre si (Holzmann e Hinz, 2005; Bovenberg e Ewijk, 2012).

Essa mudança é oriunda da preocupação com os aspectos fiscais associados aos regimes previdenciários dos servidores públicos. Esses regimes de repartição representam um componente importante do gasto público e há evidência internacional de que são mais generosos do que seus congêneres do setor privado, o que pode levar a um passivo fiscal de grande magnitude e frequentemente avaliado de forma inadequada (Ponds, Severinson e Yermo, 2011). Esse fato tem levado órgãos como o Governmental Accounting Standards Board (Gasb) a emitir normas buscando aprimorar e padronizar a mensuração dos passivos previdenciários (Mortimer e Henderson, 2014).

\subsection{A experiência internacional}

A literatura sobre os regimes previdenciários dos servidores públicos não é tão expressiva quanto a que se refere aos trabalhadores do setor privado. Adicionalmente, como aponta Lindeman (2002), há uma certa lacuna em seu arcabouço regulatório, o que é uma evidência da pouca atenção que tem recebido.

Na Alemanha o benefício aos servidores públicos é financiado em um regime de repartição simples. No entanto, observa-se um aumento dos gastos públicos decorrente da mudança do perfil demográfico da população. Nos últimos anos o número de empregados ativos jovens é cada vez menor, ao passo que o número de funcionários próximos da aposentadoria apresenta crescimento. Maurer, Mitchell e Rogalla (2009) concluem que a mudança para o regime de capitalização pode ser positiva, uma vez que irá reduzir os dispêndios públicos e gerar ganhos para o mercado de capitais.

Diferentemente do caso brasileiro, os EUA fizeram o caminho inverso em relação à previdência. Inicialmente, quando foram criados os programas previdenciários, os servidores públicos não foram cobertos e o resultado foi que muitos estados criaram seus próprios planos de previdência. Apenas após um conjunto de reformas no sistema, a maioria dos servidores 
públicos foi incluída no regime de seguridade social (Clark et al., 2009).

O Japão, país com grande parcela da população idosa, passou por reformas entre o final da década de 1980 e começo dos anos 1990 visando unificar os regimes previdenciários dos servidores públicos e dos trabalhadores do sistema privado. Motivado pela grande disparidade de regras, como idade de aposentadoria e alíquota de contribuição, o governo japonês propôs em 1985 uma reforma para unificar os sistemas. O resultado foi positivo, com redução das diferenças anteriormente existentes (Sakamoto, 2009).

No Canadá, os regimes de previdência dos servidores públicos representam uma parcela significativa dos beneficiários e dos investimentos (na parcela capitalizada) (Pozzebon, 2001). Entretanto, de forma distinta do que ocorre em vários países, parece haver pouca diferença na composição dos portfólios dos fundos públicos e privados.

No Brasil, alguns poucos estudos trataram da criação da Funpresp. Uma contribuição pioneira foi feita por Ferreira (2008), que analisou as condições que deveriam vigorar para a constituição da Funpresp. Mais recentemente, Rangel e Saboia buscaram quantificar os impactos da criação da Funpresp, porém tendo como foco os futuros funcionários públicos. No mesmo ano, Amaral, Giambiagi e Caetano (2013) abordam o tema, também, com o emprego de um modelo estocástico de simulação. Um dos resultados mais importantes é que a variabilidade nos elementos de risco, introduzida pelo novo desenho previdenciário, em particular a taxa de juros, pode trazer grandes mudanças nos valores dos benefícios previdenciários.

\subsection{Os antecedentes da criação da Funpresp}

A criação da Funpresp é mais uma etapa de uma série de reformas previdenciárias, cujas raízes devem ser buscadas no final dos anos 1980. A Constituição de 1988 previa que o servidor público poderia se aposentar com 35/30 anos de serviço se homem/mulher, com salário integral, ou, então, poderia optar por se aposentar antecipadamente, com 30/25 anos de serviço, com benefício proporcional. Além de o benefício ser integral, previa-se ainda a paridade, ou seja, todos os reajustes concedidos aos trabalhadores ativos eram concedidos aos inativos. Com a Emenda Constitucional no 20 (EC 20) de 1998, a regulamentação do RPPS sofreu alterações significativas: passou a ser exigido tempo mínimo de 10 anos no serviço público e cinco anos no cargo para concessão de aposentaria, além dos pré-requisitos de 60 anos de idade e 35 anos de contribuição (homens), e 55 anos de idade e 30 anos de contribuição (mulheres) (Rangel, 2013). Esse ato jurídico marca um novo paradigma, tendo em vista que também foi criada uma série de regras, visando o equilíbrio financeiro e atuarial dos RPPSs (Calazans et al., 2013).

Em 2003, com a Emenda Constitucional no 41 (EC 41), o sistema previdenciário brasileiro passou por mais uma reforma, que trouxe as seguintes mudanças para o RPPS: redução de 30\% no valor das pensões com valor acima do teto de benefícios do RGPS; contribuições de $11 \%$ sobre a parcela das aposentadorias superior ao teto de benefícios do RGPS; fim da 
integralidade e paridade para os futuros funcionários públicos; e utilização da média dos 80\% maiores salários desde julho de 1994 para concessão do benefício, no lugar do último salário. Finalmente, previa-se a criação de uma entidade de previdência complementar para servidores públicos, a Funpresp. Apresentam-se no quadro 1 a comparação entre as regras contributivas e de cálculo dos benefícios para os trabalhadores do setor público e do setor privado, bem como as condições de elegibilidade.

Com a Lei no 12.618 o RPPS sofreu uma importante mudança. Até então era um regime de repartição simples. Isso significa que os contribuintes em fase ativa custeavam os benefícios dos inativos. Após a mudança, passou a ser um regime misto: a parcela dos benefícios com valor até o teto do RGPS ainda será custeada no regime de repartição simples, com contribuição de $11 \%$ da folha salarial até o valor do teto. Os benefícios continuarão sendo proporcionais aos $80 \%$ maiores salários de contribuição e serão ajustados anualmente de acordo com a inflação.

O valor excedente passa a fazer parte de um regime de capitalização, em um plano de previdência complementar. O servidor público poderá contribuir com até 8,5\% do salário excedente ao teto do RGPS para a Funpresp, contando com contribuição equivalente por parte da União. O servidor poderá, ainda, fazer contribuições adicionais, sem que haja equivalência contributiva da União. Os planos da Funpresp funcionam na modalidade de contribuição definida. Portanto, não há garantia quanto ao valor do benefício. O benefício será definido de acordo com a reserva acumulada das contribuições efetuadas durante o período laboral, mais a rentabilidade desses recursos. Foram criadas duas entidades, uma para o Poder Executivo e Poder Legislativo, e uma para o Poder Judiciário, ambas sem fins lucrativos.

Quadro 1

RPPS e RGPS: comparativo de regras

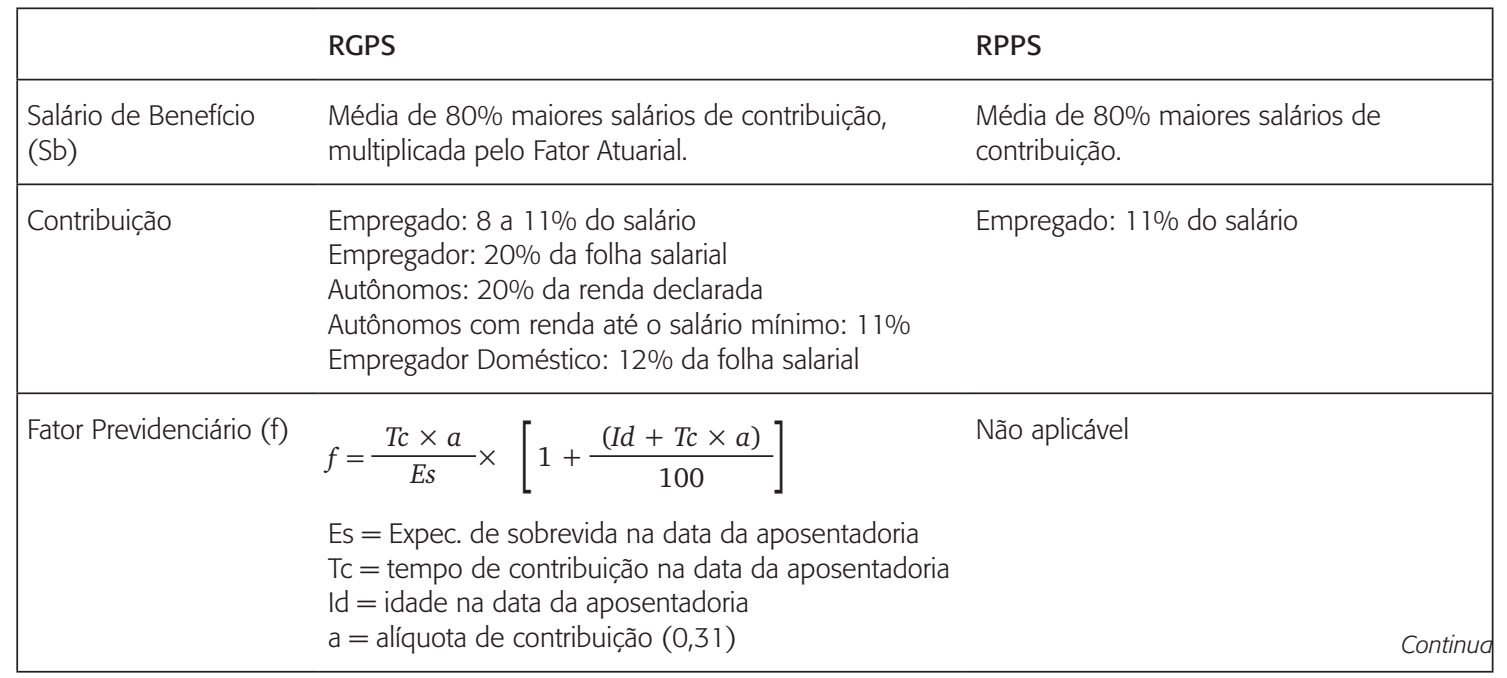




\begin{tabular}{|c|c|c|}
\hline & RGPS & RPPS \\
\hline $\begin{array}{l}\text { Aposentadoria por } \\
\text { Idade }\end{array}$ & $\begin{array}{l}\text { Elegibilidade: } \\
\text { Idade: } 65 \text { anos (H); } 60 \text { anos (M) } \\
\text { Tc: } 15 \text { anos } \\
\text { Benefício: Max [SM; Min (70\% + 1\% x TC; 100\%) x } \\
\text { Sb x f] } \\
\text { SM = Salário Mínimo }\end{array}$ & $\begin{array}{l}\text { Elegibilidade: } \\
\text { Idade: } 65 \text { anos }(\mathrm{H}) \text { e } 60 \text { anos }(\mathrm{M}) \\
\text { Tc: } 10 \text { anos de serviço público e cinco anos } \\
\text { no cargo } \\
\text { Benefício: Max [SM; 100\% x Sb] }\end{array}$ \\
\hline $\begin{array}{l}\text { Aposentadoria por } \\
\text { Tempo de Contribuição }\end{array}$ & $\begin{array}{l}\text { Elegibilidade: } 35 \text { anos }(\mathrm{H}) \text { e } 30 \text { anos }(\mathrm{M}) \\
\text { Benefício: Max [SM; 100\% x Sb x f] }\end{array}$ & $\begin{array}{l}\text { Elegibilidade: Idade: } 60 \text { anos }(\mathrm{H}) \text { e } 55 \\
\text { anos (M) } \\
\text { Tc: } 35 \text { anos (H) e } 30 \text { anos (M), } 10 \text { anos } \\
\text { de serviço público e cinco anos no cargo } \\
\text { Benefício: Max [Sm ; 100\% x Sb] }\end{array}$ \\
\hline
\end{tabular}

Fonte: MPS (2009) e MPS (2013).

A mudança na regra de aposentadoria do RPPS é válida para os novos funcionários públicos, mas os servidores que já trabalhavam no serviço público poderão migrar para o novo regime e passar a contribuir para a Funpresp. Nesse caso, ao se aposentarem, terão seu benefício composto por três componentes: a primeira parcela do RPPS, com teto definido, a segunda parcela referente ao benefício especial pela migração, e a terceira parcela, proveniente dos recursos acumulados até o momento da aposentadoria na Funpresp.

O Benefício Especial previsto na Lei no 12.618 será pago pelo RPPS, com valor proporcional ao tempo de contribuição no regime anterior à opção, durante o qual o servidor contribuiu sobre um montante superior ao teto. A base de cálculo para o Benefício Especial será a diferença entre a média dos $80 \%$ maiores salários de benefício do servidor até a data da opção, atualizadas pelo IPCA, e o teto de benefícios do RGPS. Sobre esse valor será aplicado o fator de conversão FC definido na expressão 1. Nessa equação, Tc é a quantidade de contribuições efetuadas pelo servidor ao RPPS até a data da opção e Tt é a quantidade máxima de contribuições efetuadas pelo servidor.

$$
\mathrm{FC}=\frac{\mathrm{Tc}}{\mathrm{Tt}}
$$

O valor do denominador depende do tempo de contribuição necessário para aposentadoria por tempo de contribuição. Por exemplo, um indivíduo do sexo masculino precisa trabalhar 35 anos, realizando 13 contribuições por ano. Nessa situação, o denominador é 455. Para mulheres e professores, que precisam contribuir por 30 anos, o denominador é 390. Para as professoras, que contribuem por 25 anos, o valor é 325 .

A decisão de migrar de regime implica optar pela retenção do risco financeiro, dada a possibilidade de obter uma aposentadoria de valor mais elevado. Essa escolha depende das preferências que os servidores têm no tocante ao risco de cada tipo de fundo (Brown e Weis- 
benner, 2014). Os riscos ligados à Funpresp estão relacionados à rentabilidade dos investimentos dos fundos constituídos, podendo apresentar retorno acima ou abaixo do esperado. As figuras 1 e 2 apresentam, respectivamente, o valor da aposentadoria para servidores que não optarem pela migração e para servidores que realizarem a migração. A situação retratada na figura 2 é um caso particular, em que a soma das três parcelas é igual ao benefício nas condições que prevaleciam anteriormente à mudança.

Figura 1

Aposentadoria do servidor público não optante pela migração de regime
Figura 2

Aposentadoria do servidor público optante pela migração de regime

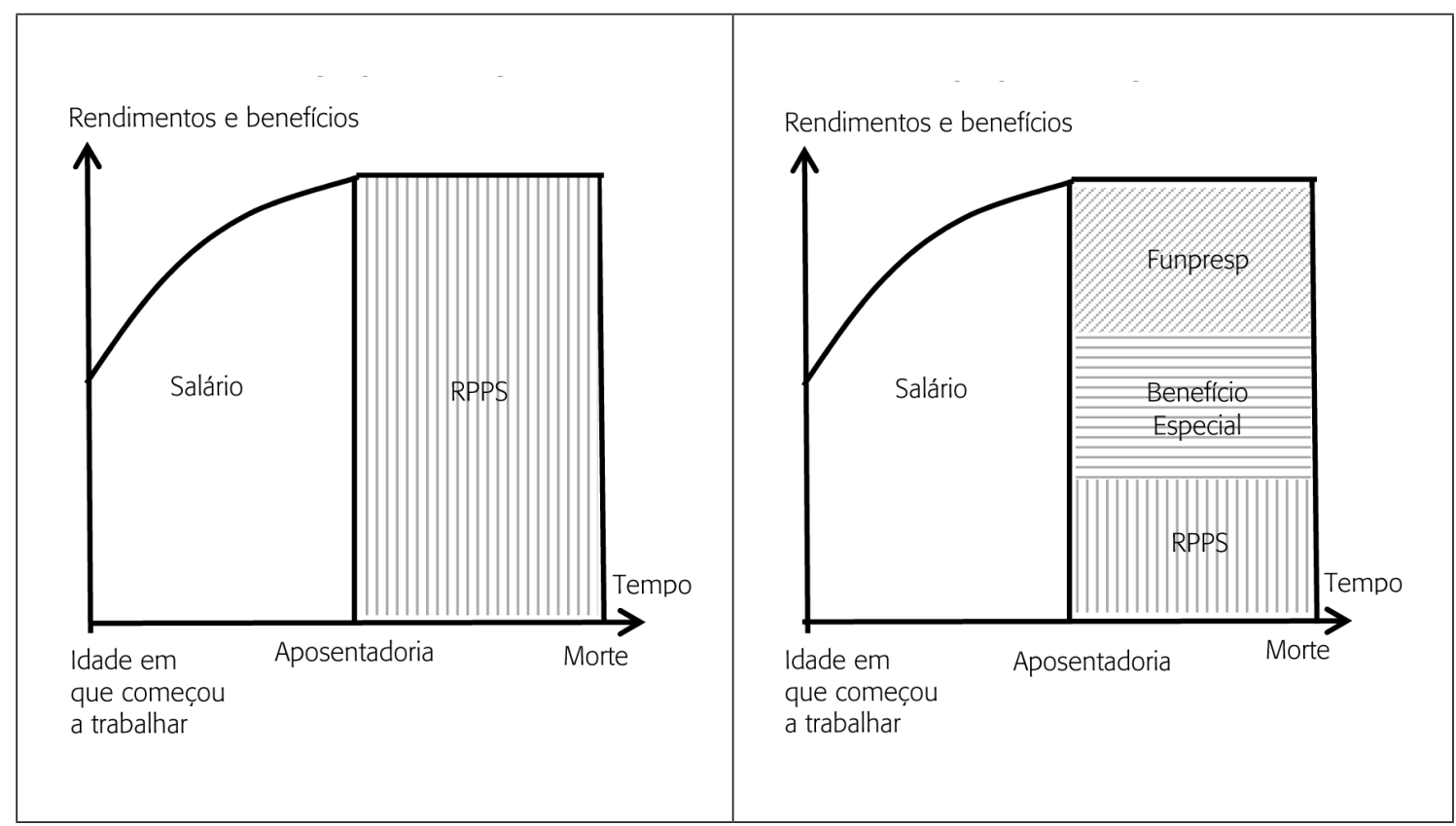

Fonte: Elaboração dos autores com base na Lei oㅜ 12.618 .

\subsection{Informações sobre os servidores públicos}

Antes de analisar os impactos da Lei no 12.618, é importante apresentar algumas características dos servidores públicos. Na tabela 1 é apresentado o quantitativo de servidores públicos federais. Cerca de 2 milhões de pessoas estão vinculadas ao RPPS da União, dos quais cerca de $54 \%$ correspondem à parcela de servidores ativos. O Poder Executivo é o grupo de maior representatividade, com mais de $92 \%$ total. 
Tabela 1

Quantitativo de servidores públicos por Poder (dez. 2012)

\begin{tabular}{|lrrrr|}
\hline Poder & \multicolumn{1}{l}{ Ativos } & \multicolumn{1}{c}{ Inativos } & Pensionistas & \multicolumn{1}{c|}{ Total } \\
\hline Executivo & 999.661 & 530.384 & 401.096 & 1.931 .141 \\
Civis & 585.910 & 379.930 & 251.675 & 1.217 .515 \\
Banco Central & 4.380 & 4.601 & 383 & 9.364 \\
Empresas Públicas & 26.918 & - & - & 26.918 \\
Sociedades de Economia Mista & 16.474 & - & - & 16.474 \\
Militares & 350.741 & 144.096 & 148.332 & 643.169 \\
Ministério Público & 15.238 & 1.757 & 706 & 17.701 \\
Legislativo & 25.828 & 7.083 & 2.657 & 35.568 \\
Judiciário & 104.971 & 19.828 & 5.921 & 130.720 \\
Total & 1.130 .460 & 557.295 & 409.674 & 2.097 .429 \\
\hline
\end{tabular}

Fonte: MPOG (2013, tabela 2.1).

Uma variável importante é a idade média dos servidores, pois, quanto mais próxima a data de aposentadoria, menos vantajosa é a troca de regime, uma vez que o período de acumulação de recursos na Funpresp seria menor. No quadro 3 é apresentada a idade média (46 anos) dos servidores públicos. Portanto, ainda faltariam 14 anos para atingir a elegibilidade da aposentadoria por tempo de contribuição. Outra variável importante é o nível salarial, pois este impacta o valor do benefício. Na tabela 2 é apresentada a distribuição dos servidores públicos civis do Poder Executivo por faixa de renda. A remuneração mensal média é de $\mathrm{R} \$ 6.122,00$, superior ao teto de benefícios do RGPS. Mais de 50\% dos servidores têm salários acima de $\mathrm{R} \$ 4.500,00$.

$$
\text { Quadro } 2
$$

Idade média dos servidores públicos civis do Poder Executivo (dez. 2012)

\begin{tabular}{|lllll|}
\hline Sexo & Ativos & Inativos & Pensionistas $^{1}$ & Total $^{\prime}$ \\
\hline Homens & 47 anos & 72 anos & 66 anos & 59 anos \\
Mulheres & 45 anos & 69 anos & 63 anos & 55 anos \\
\hline Total & 46 anos & 70 anos & 66 anos anos \\
\hline
\end{tabular}

Fonte: MPOG (2013, tabela 2.13).

1 Idade de falecimento do titular. 
Tabela 2

Servidores públicos civis ativos do Poder Executivo Federal (dez. 2012)

\begin{tabular}{|lccc|}
\hline Faixa Salarial $(\mathrm{R} \$)$ & Servidores Ativos $(\%)$ & Faixa Salarial $(\mathrm{R} \$)$ & Servidores Ativos (\%) \\
\hline Até $1.034,59$ & 1,7 & De 4.501 a 5.500 & 10,7 \\
De $1.034,59$ a 1.200 & 0 & De 5.501 a 6.500 & 6,5 \\
De 1.201 a 1.300 & 0,2 & De 6.501 a 7.500 & 6,6 \\
De 1.301 a 1.400 & 0,1 & De 7.501 a 8.500 & 8,6 \\
De 1.401 a 1.500 & 0,1 & De 8.501 a 9.500 & 3,8 \\
De 1.501 a 2.000 & 2,6 & De 9.501 a 10.500 & 2,2 \\
De 2.001 a 2.500 & 6,9 & De 10.501 a 11.500 & 2,7 \\
De 2.501 a 3.000 & 6,7 & De 11.501 a 12.500 & 3,3 \\
De 3.001 a 3.500 & 9,1 & De 12.501 a 13.000 & 1 \\
De 3.501 a 4.500 & 17,8 & Acima de 13.000 & 9,6 \\
\hline
\end{tabular}

Fonte: MPOG (2013, tabela 3.1).

\section{0 modelo}

\subsection{A composição da aposentadoria}

Ao se aposentar no antigo regime, o servidor receberia apenas o benefício do RPPS, proporcional aos $80 \%$ maiores salários de contribuição. No novo regime, o benefício total é dado pela soma de três componentes: o benefício do RPPS (limitado ao teto do RGPS), o benefício especial, oriundo das contribuições ao antigo regime (no qual o teto era superior ao valor máximo do RGPS) e o benefício calculado a partir do saldo acumulado na Funpresp. Os dois primeiros estão ligados a regimes de repartição e o terceiro, a um regime de capitalização. A seguir apresenta-se a forma de cálculo de cada componente.

\subsubsection{Valor do benefício de acordo com o antigo regime}

O valor da aposentadoria no antigo regime corresponde à média aritmética dos $80 \%$ maiores salários de contribuição ao RPPS, desde 1ํ de julho de 1994 até a data de aposentadoria apos, conforme apresentado na expressão 2. Para calcular esse valor é necessário reconstruir o fluxo de salários recebidos pelo servidor. Considerando que seu salário no instante $t$ seja $s_{t}$ e que este cresça a uma taxa real constante cs ao longo de sua vida ativa, é possível determinar o salário em cada mês, desde julho de 1994 até a data de sua aposentadoria, bem como a média SalTotal ${ }^{80 \% \text { após. }}$.

$$
\text { BenRPPSant }_{\text {apos }}=\text { SalTotal }^{80 \% \text { apos }}=
$$




\subsubsection{Valor do benefício especial}

O benefício especial BenEsp $p_{i}$ é calculado pela diferença entre a média real dos $80 \%$ maiores salários recebidos desde a entrada no serviço público SalTotal $_{i}^{80 \%}$ e o valor do teto de benefícios

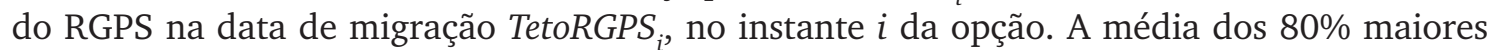
valores que excedem o teto do RGPS multiplicada pelo fator $F C$ resulta no benefício especial, de acordo com a equação 3 :

$$
\text { BenEsp }_{i}=\left(\text { SalTotal }_{i}^{80 \%}-\text { TetoRGPS }_{i}\right) \times F C
$$

\subsubsection{Valor do benefício pago pela Funpresp}

A terceira parcela, em caso de migração para o novo regime, é o benefício pago pela Funpresp. Esse termo corresponde a uma renda vitalícia calculada em um regime de capitalização, com base na rentabilidade do saldo acumulado pelo servidor, do instante de sua opção pela Funpresp até a data de aposentadoria apos. A primeira etapa do cálculo é o cômputo do saldo na data da aposentadoria. As contribuições mensais (com alíquotas $p s_{t}$ para o servidor e $p u_{t}$ para a União, esta última limitada a 8,5\%) são calculadas com base na diferença entre o Salário $s_{t}$ do servidor no instante $t$ e o valor do teto de benefícios do RGPS. A equação 4 apresenta o valor do saldo acumulado na data da aposentadoria.

$$
\text { Sld Acumulado }{ }_{\text {apos }}=\sum_{t=i}^{\text {apos }}\left(s_{t}-\text { TetoRGPS }_{t}\right) \times\left(p s_{t}+p u_{t}\right) \times(1+r)^{(\text {apos }-t)}
$$

A segunda etapa é a conversão do saldo acumulado no benefício BenFunpresp ${ }_{\text {apos }}$. Para isso é necessário o emprego de algumas expressões de matemática atuarial. Na expressão 5 , o termo FatorAtuarial apos $_{\text {corresponde à anuidade vitalícia äxy, calculada com base nas idades } x}$ do servidor e $y$ do seu cônjuge na data da aposentadoria, dada na equação 6. Essa expressão é empregada para o cálculo da pensão a ser deixada ao dependente do servidor. Os termos ${ }_{t} p_{x} \mathrm{e} p_{t}$ representam, respectivamente, as probabilidades de sobrevivência do servidor e de seu cônjuge (idades $x$ e $y$ ) por mais $t$ anos. $O$ termo $v_{t}$ corresponde ao desconto financeiro. As equações 7 a 9 são empregadas para o cômputo das anuidades vitalícias para o servidor e de seus dependentes. Para maiores detalhes, ver Bowers Jr. e colaboradores (1997) ou Parmenter (1999).

$$
\begin{aligned}
& \text { BenFunpresp apos }=\frac{\text { SldAcumulado }_{\text {apos }}}{\text { FatorAtuarial }} \text { apos } \\
& \ddot{\mathrm{a}}_{x y}=\ddot{\mathrm{a}}_{x}+70 \% \times\left(\ddot{\mathrm{a}}_{y}-\ddot{\mathrm{a}}_{x, y}\right) \\
& \ddot{\mathrm{a}}_{x}=\sum_{t=0}^{\text {morte }} v^{t} \times{ }_{t} p_{x} \\
& \ddot{\mathrm{a}}_{y}=\sum_{t=0}^{\text {morte }} v^{t} \times{ }_{t} p_{y} \\
& \ddot{\mathrm{a}}_{x, y}=\sum_{t=0}^{\text {morte }} v^{t} \times{ }_{t} p_{x, y}
\end{aligned}
$$




\subsection{Premissas do modelo}

Uma vez exposto o modelo, é necessário explicitar as premissas empregadas nos cálculos. Essas premissas estão de acordo com a prática de mercado de entidades de previdência complementar no Brasil e alinhadas com a legislação vigente, conforme as Resoluções $n^{\circ}$ 9, de 29/11/2012, e no 10, de 19/12/2012, expedidas pelo Conselho Nacional de Previdência Complementar (CNPC). São apresentadas a seguir as premissas adotadas no Cenário Base:

- Taxa de desconto (r): $3 \%$ a.a.;

- Crescimento Salarial (cs): $2 \%$;

、 Tábua de Mortalidade: AT-2000, específica por sexo;

v Idade de aposentadoria: 60 anos;

- Idade de entrada no serviço público: 25 anos;

- Percentual de casados: 100\%;

- Diferença de idade entre homens e mulheres: 4 anos;

v Percentual de reversão do benefício em pensão: 70\%.

\section{Resultados}

\subsection{Cenário base}

Na seção 2.3 mostrou-se que os servidores ativos têm idade média de 46 anos idade e salário médio de $\mathrm{R} \$ 6.122,00$. O primeiro conjunto de resultados (para ambos os sexos), denominado de cenário base, é calculado para este servidor médio, com o emprego das premissas listadas na seção 3.2. Com base no salário atual e na data de aposentadoria, são apresentados os valores do benefício previdenciário (no antigo e no novo regimes), bem como as Taxas de Reposição (TR) (relação entre o primeiro benefício e o último salário), de forma similar à apresentada em Binswanger e Schunk (2011). Esse é um indicador de uso bastante difundido na literatura previdenciária, por sua facilidade de interpretação e relevância para o segurado. Para ambos os sexos a TR é elevada, sendo mais alta no antigo regime. Para o servidor médio a mudança de regime não é vantajosa, pois haveria uma redução de $17 \%$ do valor do benefício de aposentadoria para os homens e de $15 \%$ para as mulheres. 
Tabela 3

Benefício previdenciário e taxa de reposição (servidor médio: antigo e novo regimes)

\begin{tabular}{|c|c|c|c|c|c|c|c|c|}
\hline \multirow{2}{*}{ Sexo } & \multirow{2}{*}{ Idade } & \multirow{2}{*}{$\begin{array}{c}\text { Salário } \\
\text { atual (R\$) }\end{array}$} & \multirow{2}{*}{$\begin{array}{c}\text { Último } \\
\text { salário } \\
\text { (R\$) }\end{array}$} & \multicolumn{2}{|c|}{ Antigo regime } & \multicolumn{2}{|c|}{ Novo regime } & \multirow{2}{*}{$\begin{array}{l}\text { Dif. entre } \\
\text { TRs (\%) }\end{array}$} \\
\hline & & & & $\begin{array}{c}\text { Benefício } \\
\text { (RS) }\end{array}$ & TR (\%) & $\begin{array}{c}\text { Benefício } \\
(\mathrm{R} \$)\end{array}$ & TR (\%) & \\
\hline $\mathrm{H}$ & 46 & 6.122 & 8.077 & 6.310 & 78 & 5.261 & 65 & -17 \\
\hline M & 46 & 6.122 & 8.077 & 6.310 & 78 & 5.388 & 67 & -15 \\
\hline
\end{tabular}

Fonte: Elaboração dos autores.

Conforme exposto anteriormente, no novo regime o benefício total é composto pela soma do benefício do RPPS (limitado a R $4.159,00$ ), do benefício especial e do benefício da Funpresp. Na tabela 4 apresenta-se a participação relativa de cada componente, para o servidor médio. Nota-se que o componente mais importante é o benefício do RPPS, que responde por quase $80 \%$ do benefício total.

Tabela 4

Composição do benefício (servidor médio: novo regime)

\begin{tabular}{|ccccc|}
\hline & $\begin{array}{c}\text { Benefício total } \\
(\mathrm{R} \$)\end{array}$ & Benefício do RPPS (\%) & Benefício Especial (\%) & Benefício da Funpresp (\%) \\
\hline $\mathrm{H}$ & 5.261 & 79 & 13 & 8 \\
$\mathrm{M}$ & 5.388 & 77 & 15 & 8 \\
\hline
\end{tabular}

Fonte: Elaboração dos autores.

\subsection{Extensões}

\subsubsection{Decisão contributiva}

Nesta seção alteram-se algumas das hipóteses e premissas empregadas no cenário base. A primeira modificação refere-se à decisão contributiva do servidor. Nas tabelas 5 e 6 mostram-se os resultados caso o servidor opte por contribuir com apenas $6 \%$ de seu salário, ao invés dos $8,5 \%$ empregados na seção 4.1. Nas tabelas 7 e 8 são reportados os resultados na hipótese de o funcionário público resolver contribuir com $11 \%$ de seu salário. É importante ressaltar que, nesse caso, a alíquota de contribuição da União está limitada ao teto de 8,5\% do salário. Conforme era esperado, a diminuição das contribuições à Funpresp reduz ainda mais o benefício que o servidor médio teria em caso de mudança de regime. Em contrapartida, a elevação no 
nível de contribuição não apresentou um impacto significativo na composição do benefício no novo regime. O motivo é que o servidor médio tem 46 anos, o que faz com que o período de acumulação das contribuições à Funpresp seja relativamente reduzido.

\section{Tabela 5}

Benefício e taxa de reposição (servidor médio: contribuição de 6\%)

\begin{tabular}{|c|c|c|c|c|c|c|c|c|}
\hline & \multirow[b]{2}{*}{ Idade } & \multirow[b]{2}{*}{$\begin{array}{c}\text { Salário } \\
\text { atual }(R \$)\end{array}$} & \multirow[b]{2}{*}{$\begin{array}{c}\text { Último } \\
\text { salário }(R \$)\end{array}$} & \multicolumn{2}{|c|}{ Antigo regime } & \multicolumn{2}{|c|}{ Novo regime } & \multirow[b]{2}{*}{$\begin{array}{c}\text { Dif. entre } \\
\text { TRs (\%) }\end{array}$} \\
\hline & & & & $\begin{array}{c}\text { Benefício } \\
(\mathrm{R} \$)\end{array}$ & TR (\%) & $\begin{array}{l}\text { Benefício } \\
\quad(\mathrm{R} \$)\end{array}$ & TR (\%) & \\
\hline $\mathrm{H}$ & 46 & 6.122 & 8.077 & 6.310 & 78 & 5.137 & 64 & -19 \\
\hline M & 46 & 6.122 & 8.077 & 6.310 & 78 & 5.260 & 65 & -17 \\
\hline
\end{tabular}

Fonte: Elaboração dos autores.

Tabela 6

Composição do benefício total no novo regime (servidor médio: contribuição de 6\%)

\begin{tabular}{|ccccc|}
\hline & Benefício total (R\$) & Benefício do RPPS (\%) & Benefício Especial (\%) & Benefício Funpresp (\%) \\
\cline { 2 - 5 }$H$ & 5.137 & 81 & 13 & 6 \\
$\mathrm{M}$ & 5.260 & 79 & 15 & 6 \\
\hline
\end{tabular}

Fonte: Elaboração dos autores.

Tabela 7

Benefício e taxa de reposição (servidor médio: contribuição de 11\%)

\begin{tabular}{|c|c|c|c|c|c|c|c|c|}
\hline & \multirow[b]{2}{*}{ Idade } & \multirow[b]{2}{*}{$\begin{array}{c}\text { Salário } \\
\text { atual (R\$) }\end{array}$} & \multirow[b]{2}{*}{$\begin{array}{c}\text { Último } \\
\text { salário }(\mathrm{R} \$)\end{array}$} & \multicolumn{2}{|c|}{ Antigo regime } & \multicolumn{2}{|c|}{ Novo regime } & \multirow[b]{2}{*}{$\begin{array}{c}\text { Dif. entre } \\
\text { TRs (\%) }\end{array}$} \\
\hline & & & & $\begin{array}{c}\text { Benefício } \\
(\mathrm{R} \$)\end{array}$ & TR (\%) & $\begin{array}{c}\text { Benefício } \\
(\mathrm{R} \$)\end{array}$ & TR (\%) & \\
\hline $\mathrm{H}$ & 46 & 6.122 & 8.077 & 6.310 & 78 & 5.324 & 66 & -16 \\
\hline M & 46 & 6.122 & 8.077 & 6.310 & 78 & 5.452 & 67 & -14 \\
\hline
\end{tabular}

Fonte: Elaboração dos autores.

Tabela 8

Composição do benefício total no novo regime (servidor médio: contribuição de 11\%)

\begin{tabular}{|ccccc|}
\hline & Benefício total (R\$) & Benefício do RPPS (\%) & Benefício Especial (\%) & Benefício Funpresp (\%) \\
\hline H & 5.324 & 78 & 13 & 9 \\
M & 5.452 & 76 & 15 & 9 \\
\hline
\end{tabular}

Fonte: Elaboração dos autores. 


\subsubsection{Taxa de juros}

Outra variável importante a ser considerada na quantificação do benefício que o servidor optante pela migração obteria é a taxa de juros obtida para os recursos oriundos das contribuições à Funpresp. De forma distinta da alíquota de contribuição à Funpresp, que é uma decisão do servidor público, a taxa de juros é resultado das escolhas feitas pelo gestor dos recursos. Dessa forma, é exógena ao trabalhador, mas afeta-o diretamente. Nas tabelas 9 a 12 são apresentados os resultados para as taxas de juros anuais reais de $4,5 \%$ ou $6 \%$, mantendo-se as demais premissas do cenário base.

Tabela 9

Benefício e taxa de reposição (servidor médio: taxa de juros de 4,5\%)

\begin{tabular}{|c|c|c|c|c|c|c|c|c|}
\hline & \multirow[b]{2}{*}{ Idade } & \multirow[b]{2}{*}{$\begin{array}{c}\text { Salário } \\
\text { atual }(\mathrm{R} \$)\end{array}$} & \multirow[b]{2}{*}{$\begin{array}{c}\text { Último } \\
\text { salário (R\$) }\end{array}$} & \multicolumn{2}{|c|}{ Antigo regime } & \multicolumn{2}{|c|}{ Novo regime } & \multirow[b]{2}{*}{$\begin{array}{l}\text { Dif. entre } \\
\text { TRs (\%) }\end{array}$} \\
\hline & & & & $\begin{array}{l}\text { Benefício } \\
\text { (R\$) }\end{array}$ & TR (\%) & $\begin{array}{l}\text { Benefício } \\
\text { (R\$) }\end{array}$ & TR (\%) & \\
\hline $\mathrm{H}$ & 46 & 6.122 & 8.077 & 6.310 & 78 & 5.404 & 67 & -14 \\
\hline M & 46 & 6.122 & 8.077 & 6.310 & 78 & 5.530 & 68 & -12 \\
\hline
\end{tabular}

Fonte: Elaboração dos autores.

Tabela 10

Composição do benefício total no novo regime (servidor médio: taxa de juros de 4,5\%)

\begin{tabular}{|ccccc|}
\hline & Benefício total (R\$) & Benefício do RPPS (\%) & Benefício Especial (\%) & Benefício Funpresp (\%) \\
\hline H & 5.404 & 77 & 13 & 10 \\
$\mathrm{M}$ & 5.530 & 75 & 14 & 10 \\
\hline
\end{tabular}

Fonte: Elaboração dos autores.

Tabela 11

Benefício e taxa de reposição (servidor médio: taxa de juros de 6\%)

\begin{tabular}{|c|c|c|c|c|c|c|c|c|}
\hline & \multirow[b]{2}{*}{ Idade } & \multirow[b]{2}{*}{$\begin{array}{c}\text { Salário } \\
\text { atual }(\mathrm{R} \$)\end{array}$} & \multirow[b]{2}{*}{$\begin{array}{c}\text { Último } \\
\text { salário }(R \$)\end{array}$} & \multicolumn{2}{|c|}{ Antigo regime } & \multicolumn{2}{|c|}{ Novo regime } & \multirow[b]{2}{*}{$\begin{array}{l}\text { Dif. entre } \\
\text { TRs (\%) }\end{array}$} \\
\hline & & & & $\begin{array}{l}\text { Benefício } \\
(\mathrm{R} \$)\end{array}$ & TR (\%) & $\begin{array}{c}\text { Benefício } \\
(\mathrm{R} \$)\end{array}$ & TR (\%) & \\
\hline $\mathrm{H}$ & 46 & 6.122 & 8.077 & 6.310 & 78 & 5.582 & 69 & -12 \\
\hline M & 46 & 6.122 & 8.077 & 6.310 & 78 & 5.707 & 71 & -10 \\
\hline
\end{tabular}

Fonte: Elaboração dos autores. 
Tabela 12

Composição do benefício total no novo regime (servidor médio: taxa de juros de 6\%)

\begin{tabular}{|ccccc|}
\hline & Benefício total (R\$) & Benefício do RPPS (\%) & Benefício Especial (\%) & Benefício Funpresp (\%) \\
\hline $\mathrm{H}$ & 5.582 & 75 & 12 & 13 \\
$\mathrm{M}$ & 5.707 & 73 & 14 & 13 \\
\hline
\end{tabular}

Fonte: Elaboração dos autores.

Alterações no esforço contributivo têm impacto pouco significativo sobre o valor do benefício. O motivo é que todos os cálculos são feitos para um servidor médio, com idade de 46 anos. Dessa forma, o período de acumulação de recursos da parcela capitalizada do benefício (dada pela Funpresp) é reduzido em face do total da vida ativa. O segundo motivo é que o benefício da Funpresp não é muito expressivo ante o benefício total. Com exceção de uma situação, a parcela do RPPS representa sempre mais de 75\% do benefício total. Isso explica o fato de alterações nessa premissa pouco impactarem o benefício. Raciocínio análogo aplica-se às taxas de juros, embora seu efeito seja pouco maior do que aquele verificado para a decisão contributiva. Também se nota pouca diferença entre gêneros.

\subsection{Quais variáveis afetam a decisão de aderir ao novo regime? Resultados para diferentes idades e níveis de renda}

Todos os cálculos das duas subseções anteriores foram feitos para um servidor representativo, com idade e remunerações médias. No entanto, algumas variáveis podem afetar os resultados e por isso merecem atenção. A primeira é a idade. Servidores mais novos que optarem pelo novo regime acumularão recursos na parcela capitalizada por mais tempo. Serão mais afetados por mudanças nas alíquotas de contribuição ou nas taxas de juros. Por outro lado, para servidores mais idosos, a parcela do benefício especial será mais relevante e a parcela da Funpresp menos representativa. De forma correlata, o salário também merece atenção. Servidores com salários mais elevados tendem a ser mais afetados em caso de migração para o novo regime. O motivo é a existência de um valor máximo para o benefício, igual ao do teto do RGPS.

Para tentar quantificar a importância da idade e da remuneração, nesta seção os cálculos são feitos para diferentes perfis de servidores, com idades de 30, 35, 40, 45 e 50 anos e salários de 3, 5, 10 e 15 mil reais, o que configura um total de 20 indivíduos representativos. Nos gráficos 1 e 2 é apresentada a redução calculada no benefício do servidor que optar pela mudança, comparativamente ao benefício recebido no antigo regime, considerando as hipóteses e a metodologia expostas na seção 3 (contribuição de 8,5\% do salário, taxa de desconto de $3 \%$ e crescimento salarial de $2 \%$ ao ano).

Observa-se que as perdas relativas para os optantes do novo regime são bastante similares para homens e mulheres. Quanto mais elevada é a renda, mais acentuada é a diferença entre o benefício para os dois regimes. Os servidores do sexo masculino com 30 anos de idade apresentam os piores resultados em todos os níveis de salário. Já os servidores, de ambos os sexos, com 40 anos de idade e salário de $\mathrm{R} \$ 3.000,00$ apresentam o melhor resultado relativo, pois serão indiferentes à mudança, dado que não sofrem perdas. 


\section{Gráfico 1}

Diferença percentual no benefício (antigo regime e novo regime) por idade e nível de renda: homens

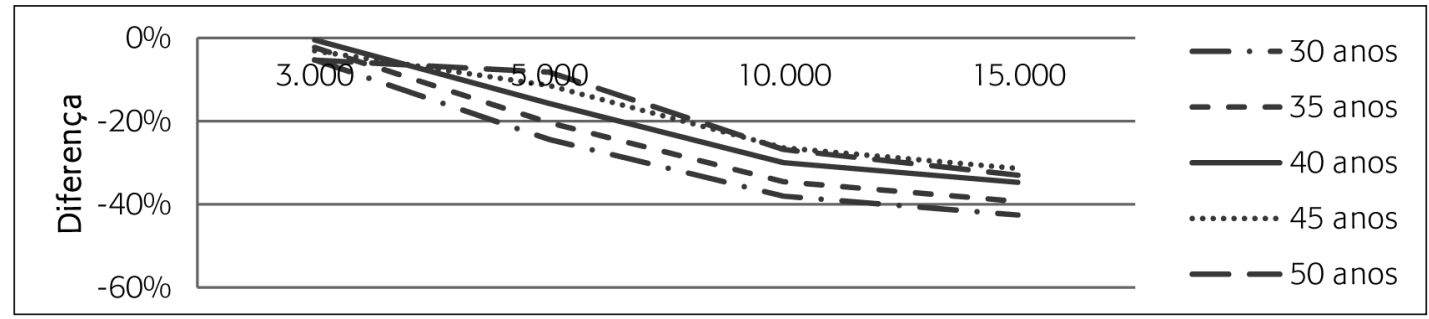

Fonte: Elaboração dos autores.

Gráfico 2

Diferença percentual no benefício (antigo regime e novo regime) por idade e nível de renda: mulheres

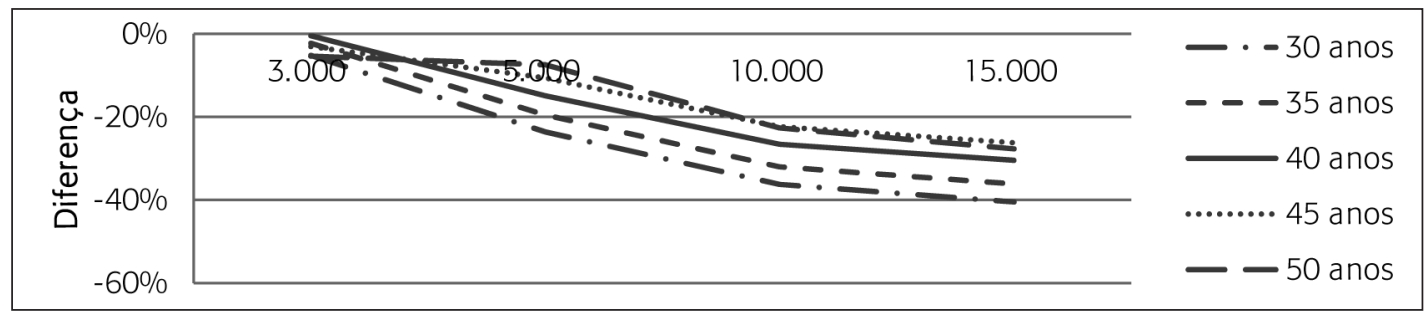

Fonte: Elaboração dos autores.

Nos gráficos 3 e 4 apresentam-se os resultados para o mesmo grupo de servidores, porém alterando-se a alíquota de contribuição para $11 \%$ do salário. A opção pelo novo regime ainda se mostra desfavorável aos funcionários públicos, porém com perdas relativamente menores, devido à influência do maior volume de contribuições.

\section{Gráfico 3}

Diferença percentual no benefício (antigo regime e novo regime) por idade e nível de renda $-11 \%$ de contribuição: homens

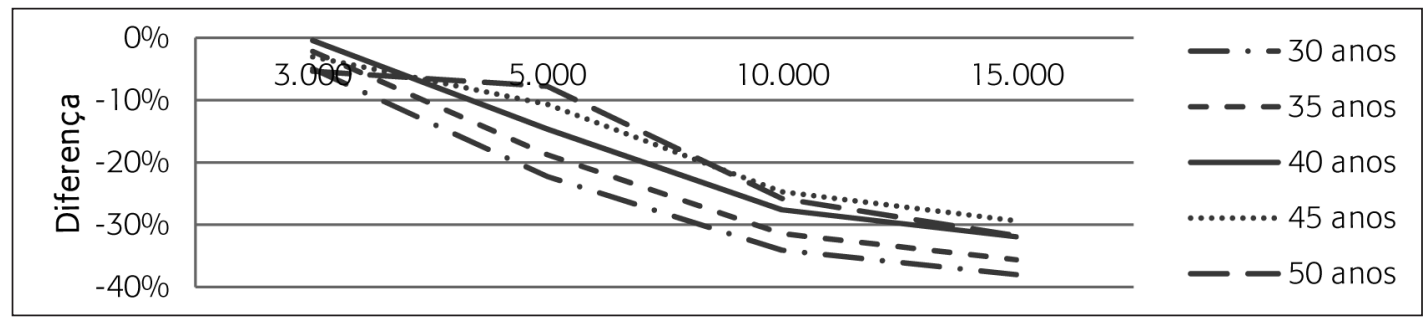

Fonte: Elaboração dos autores. 
Gráfico 4

Diferença percentual no benefício (antigo regime e novo regime) por idade e nível de renda - 11\% de contribuição: mulheres

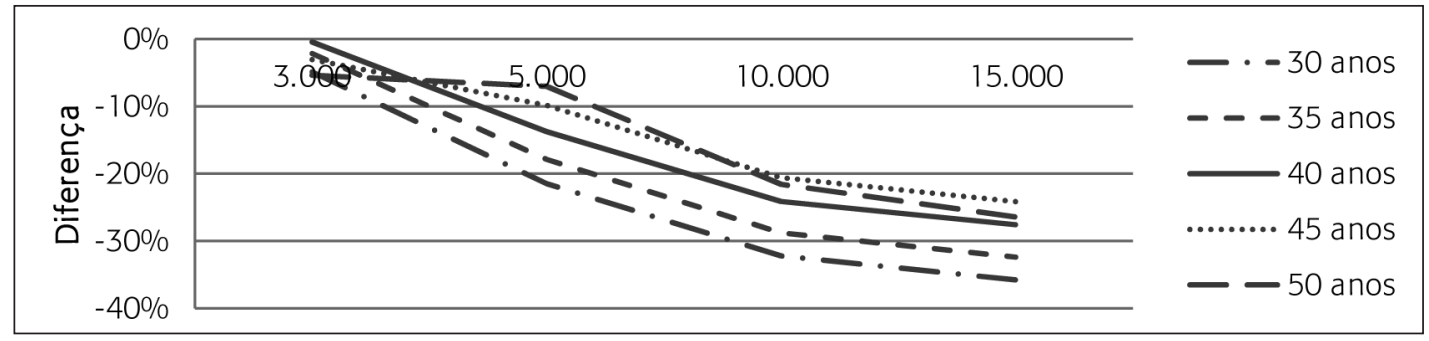

Fonte: Elaboração dos autores.

Nos gráficos 5 e 6 apresenta-se a quantificação da influência da taxa de desconto, quando esta é alterada para $6 \%$. Os valores obtidos com essa taxa maior levam a perdas menores com a mudança de regime. Em um caso (mulheres de 30 anos com renda mais elevada) há até um pequeno ganho. No entanto, é preciso enfatizar que retornos reais próximos a $6 \%$ são muito pouco prováveis, particularmente quando o horizonte de tempo é muito grande.

\section{Gráfico 5}

Diferença percentual no benefício (antigo regime e novo regime) por idade e nível de renda - taxa de desconto de 6\%: homens

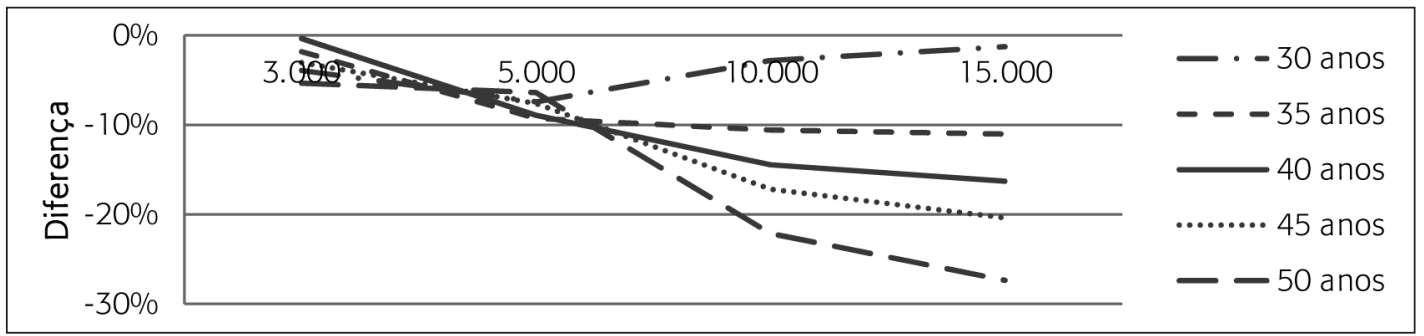

Fonte: Elaboração dos autores.

Gráfico 6

Diferença percentual no benefício (antigo regime e novo regime) por idade e nível de renda - taxa de desconto de 6\%: mulheres

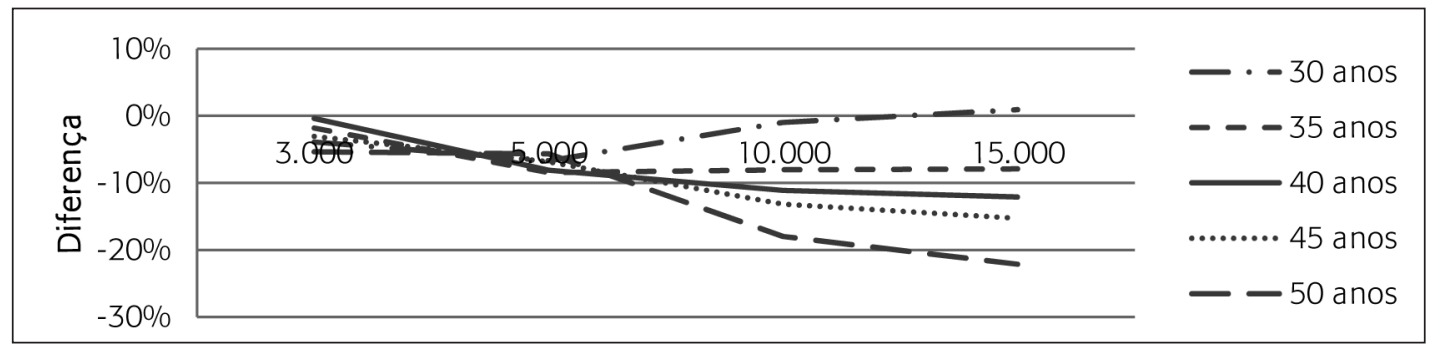

Fonte: Elaboração dos autores. 
Alterações na taxa de desconto e no nível de contribuição impactam diretamente a parcela de benefício que será paga pela Funpresp. No entanto, não impactam o benefício estimado para o RPPS e o benefício especial. Para um grande número de servidores essas parcelas compõem a maior parte da renda que o servidor terá na aposentadoria. A premissa com maior influência sobre essa parcela é a taxa de crescimento salarial. Os gráficos 7 e 8 apresentam os resultados para um cenário mais pessimista, em que os salários têm crescimento real igual a zero. O padrão é similar àquele verificado anteriormente, em que as perdas mais expressivas são verificadas para os servidores de renda mais elevada.

\section{Gráfico 7}

Diferença entre o benefício de aposentadoria estimado antes e após a Lei no 12.618 para indivíduos do sexo masculino ( $0 \%$ crescimento salarial)

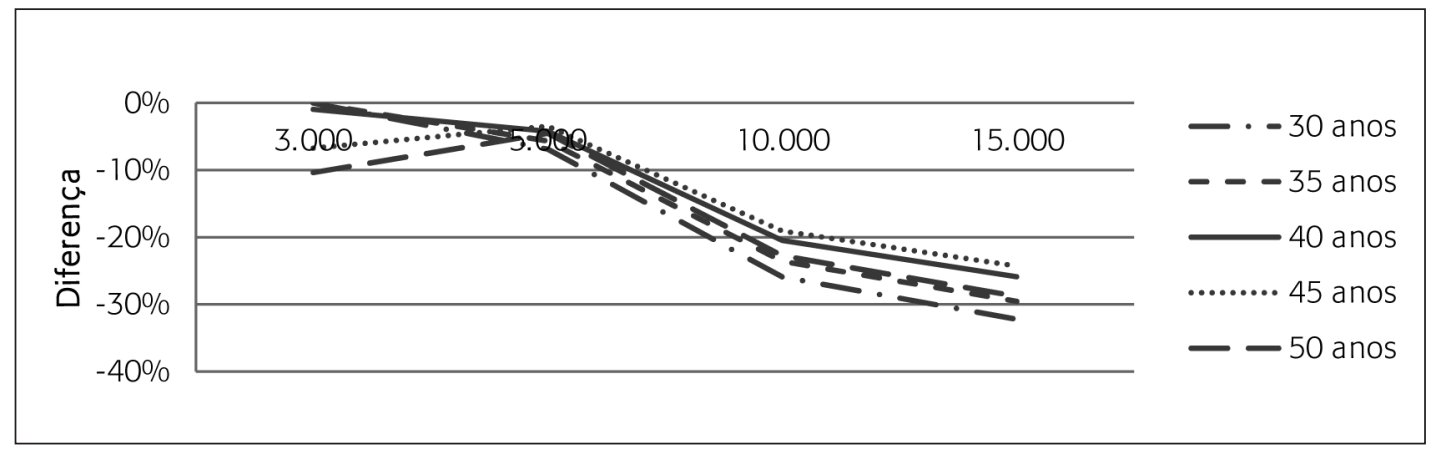

Fonte: Elaboração dos autores.

Gráfico 8

Diferença entre o benefício de aposentadoria estimado antes e após a Lei oo 12.618 para indivíduos do sexo feminino ( $0 \%$ crescimento salarial)

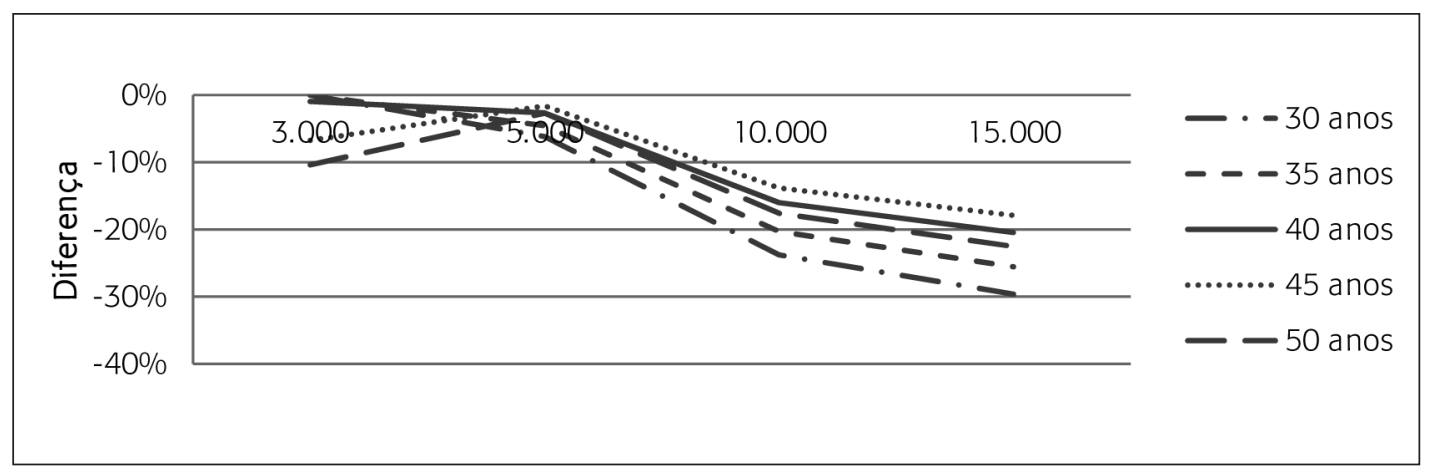

Fonte: Elaboração dos autores. 


\section{5. É possível não ter perdas com a mudança para o novo regime?}

Os resultados reportados na seção anterior mostram que na grande maioria dos casos analisados a mudança para o novo regime acarreta redução do benefício, ou seja, gera perdas ao optante. Esse resultado não é surpreendente, tendo em vista que o principal objetivo do governo era justamente reduzir os gastos com os RPPS. Esses resultados motivam a seguinte questão: haverá alguma combinação de parâmetros para os quais os servidores que aderirem à Funpresp estariam ao menos tão bem quanto no antigo regime? Esta seção tem por objetivo tentar responder a essa pergunta, para algumas combinações de idades, salários, alíquotas de contribuição e taxas de desconto.

Inicialmente, analisa-se o impacto da decisão contributiva do trabalhador. Ou seja, calcula-se qual deveria ser a alíquota de contribuição necessária à Funpresp para que o valor do benefício do servidor médio não tenha redução, considerando-se novamente as condições do cenário base. Ou seja, crescimento salarial de $2 \%$ e taxa de desconto de $3 \%$. Seria necessário um enorme esforço contributivo, com a decisão de contribuir com 51\% do salário (homens) e $45 \%$ (mulheres) para que não ocorressem perdas, conforme reportado na tabela 13 . Nesse caso, a parcela do benefício da Funpresp aumentaria para cerca de $22 \%$, devido ao maior montante contribuído. Obviamente, é uma situação extremamente improvável.

\section{Tabela 13}

Alíquota de contribuição necessária para não haver redução no benefício - servidor médio - cenário base

\begin{tabular}{|c|c|c|c|c|c|c|c|c|c|}
\hline & Idade & $\begin{array}{c}\text { Salário } \\
\text { Atual (R\$) }\end{array}$ & $\begin{array}{c}\text { Último } \\
\text { Salário } \\
(\mathrm{R} \$)\end{array}$ & $\begin{array}{c}\text { Benef. } \\
\text { Antigo } \\
\text { regime }(R \$)\end{array}$ & $\begin{array}{c}\text { Aliq. Contrib. } \\
\text { Necessária } \\
(\%)\end{array}$ & $\begin{array}{l}\text { Benef. Novo } \\
\text { regime }(\mathrm{R} \$)\end{array}$ & $\begin{array}{c}\text { Benef. } \\
\text { RPPS (\%) }\end{array}$ & $\begin{array}{c}\text { Benef. } \\
\text { Especial } \\
(\%)\end{array}$ & $\begin{array}{c}\text { Benef. } \\
\text { Funpresp } \\
\text { (\%) }\end{array}$ \\
\hline $\mathrm{H}$ & 46 & 6.122 & 8.077 & 6.310 & 45 & 6.319 & 66 & 11 & 23 \\
\hline$M$ & 46 & 6.122 & 8.077 & 6.310 & 51 & 5.707 & 66 & 12 & 22 \\
\hline
\end{tabular}

Fonte: Elaboração dos autores.

Na tabela 14 esse resultado é estendido, com a apresentação das alíquotas de contribuição necessárias para diversos perfis de servidores de ambos os sexos, com idade de 35 a 50 anos e salários de 5 e 10 mil reais. Os resultados mostram que, dadas as premissas do cenário base, a alíquota de contribuição necessária para que não ocorressem perdas seria muito elevada. A menor contribuição necessária seria de 34\%, para uma servidora de 35 anos com salário de $\mathrm{R} \$ 10.000,00$. A maior contribuição seria de 74\%, para um servidor de 50 anos com salário de $\mathrm{R} \$ 10.000,00$. Considerando-se que essa é uma contribuição adicional àquela feita para o regime básico, também parece pouco provável que servidores, particularmente os mais idosos, decidam fazer tamanho esforço contributivo. 
Tabela 14

Alíquota de contribuição necessária para não haver redução no benefício - diferentes perfis de servidores

\begin{tabular}{|c|c|c|c|c|c|c|c|c|c|}
\hline & \multirow[b]{2}{*}{ Idade } & \multirow[b]{2}{*}{$\begin{array}{c}\text { Salário } \\
\text { Atual (R\$) }\end{array}$} & \multirow{2}{*}{$\begin{array}{l}\text { Último } \\
\text { Salário } \\
\text { (R\$) }\end{array}$} & \multirow{2}{*}{$\begin{array}{c}\text { Benefício } \\
\text { Regra Antiga } \\
\text { (R\$) }\end{array}$} & \multirow{2}{*}{$\begin{array}{l}\text { Aliq. Contrib. } \\
\text { Necessária } \\
(\%) .\end{array}$} & \multirow{2}{*}{$\begin{array}{c}\text { Benefício } \\
\text { Regra Nova } \\
\text { (R\$) }\end{array}$} & \multicolumn{3}{|c|}{ Composição do Benefício } \\
\hline & & & & & & & $\begin{array}{l}\text { RPPS } \\
(\%)\end{array}$ & $\begin{array}{c}\text { Especial } \\
(\%)\end{array}$ & $\begin{array}{c}\text { Funpresp } \\
(\%)\end{array}$ \\
\hline M & 35 & 5.000 & 8.203 & 6.306 & 41 & 6.317 & 66 & 3 & 31 \\
\hline M & 35 & 10.000 & 16.406 & 12.611 & 37 & 12.751 & 33 & 11 & 56 \\
\hline M & 40 & 5.000 & 7.430 & 5.706 & 44 & 5.720 & 73 & 4 & 24 \\
\hline M & 40 & 10.000 & 14.859 & 11.412 & 40 & 11.423 & 36 & 17 & 46 \\
\hline M & 50 & 5.000 & 6.095 & 4.899 & 60 & 4.906 & 85 & 4 & 11 \\
\hline M & 50 & 10.000 & 12.190 & 9.797 & 74 & 9.823 & 42 & 24 & 34 \\
\hline $\mathrm{F}$ & 35 & 5.000 & 8.203 & 6.306 & 39 & 6.329 & 66 & 3 & 31 \\
\hline $\mathrm{F}$ & 35 & 10.000 & 16.406 & 12.611 & 34 & 12.726 & 33 & 13 & 54 \\
\hline $\mathrm{F}$ & 40 & 5.000 & 7.430 & 5.706 & 41 & 5.718 & 73 & 4 & 23 \\
\hline $\mathrm{F}$ & 40 & 10.000 & 14.859 & 11.412 & 36 & 11.470 & 36 & 20 & 44 \\
\hline $\mathrm{F}$ & 50 & 5.000 & 6.095 & 4.899 & 53 & 4.900 & 85 & 5 & 10 \\
\hline $\mathrm{F}$ & 50 & 10.000 & 12.190 & 9.797 & 62 & 9.815 & 42 & 28 & 30 \\
\hline
\end{tabular}

Fonte: Elaboração dos autores.

O último exercício feito tem como objeto a taxa de juros; valores mais elevados aumentam a aposentadoria à qual o servidor terá direito. Novamente, a análise se inicia pelo servidor médio, no cenário base. Na tabela 14 mostra-se que para os homens a taxa de juros necessária para que não ocorressem perdas no seu benefício de aposentadoria com a mudança de regime seria de $10,2 \%$ ao ano. Para as mulheres o valor seria de 9,6\%. A tabela 14 apresenta os resultados para a taxa de juros necessária, para os mesmos perfis reportados na tabela 12. A taxa de juros para que não ocorressem perdas seria muito elevada. O menor valor encontrado é de 6,7\%, para uma servidora de 35 anos com salário de $\mathrm{R} \$ 10.000,00$; a maior seria a 13,9\%, para um servidor de 50 anos com salário de R\$ 10.000,00. É importante notar que essas são taxas de juros reais médias, que devem se manter por todo o período de acumulação de recursos. Assim como já havia ocorrido com as alíquotas contributivas, é altamente improvável que esses valores venham a ser verificados. 
Tabela 15

Taxa de juros necessária para não haver redução no benefício - servidor médio - cenário base

\begin{tabular}{|c|c|c|c|c|c|c|c|c|c|}
\hline & \multirow[b]{2}{*}{ Idade } & \multirow{2}{*}{$\begin{array}{c}\text { Salário } \\
\text { Atual (R\$) }\end{array}$} & \multirow{2}{*}{$\begin{array}{c}\text { Último } \\
\text { Salário } \\
(R \$)\end{array}$} & \multirow{2}{*}{$\begin{array}{c}\text { Benefício } \\
\text { Regra Antiga } \\
(\mathrm{R} \$)\end{array}$} & \multirow{2}{*}{$\begin{array}{c}\text { Taxa de } \\
\text { juros (\%) } \\
\text { a.a. }\end{array}$} & \multirow{2}{*}{$\begin{array}{c}\text { Benefício } \\
\text { Regra Nova } \\
(\mathrm{R} \$)\end{array}$} & \multicolumn{3}{|c|}{ Composição do Benefício (\%) } \\
\hline & & & & & & & RPPS & Especial & Funpresp \\
\hline M & 46 & 6.122 & 8.077 & 6.310 & 10,2 & 6.326 & 66 & 11 & 23 \\
\hline $\mathrm{F}$ & 46 & 6.122 & 8.077 & 6.310 & 9,6 & 6.312 & 66 & 12 & 22 \\
\hline
\end{tabular}

Fonte: Elaboração dos autores.

Tabela 16

Taxa de desconto necessária para não haver redução no benefício - diferentes perfis de servidores

\begin{tabular}{|c|c|c|c|c|c|c|c|c|c|}
\hline & \multirow[b]{2}{*}{ Idade } & \multirow{2}{*}{$\begin{array}{l}\text { Salário Atual } \\
\text { (R\$) }\end{array}$} & \multirow{2}{*}{$\begin{array}{c}\text { Último } \\
\text { Salário } \\
(R \$)\end{array}$} & \multirow{2}{*}{$\begin{array}{c}\text { Benefício } \\
\text { Regra Antiga } \\
\text { (R\$) }\end{array}$} & \multirow{2}{*}{$\begin{array}{c}\text { Taxa de } \\
\text { juros (\%) } \\
\text { a.a. }\end{array}$} & \multirow{2}{*}{$\begin{array}{c}\text { Benefício } \\
\text { Regra Nova } \\
(\mathrm{R} \$)\end{array}$} & \multicolumn{3}{|c|}{ Composição do Benefício (\%) } \\
\hline & & & & & & & RPPS & Especial & Funpresp \\
\hline M & 35 & 5.000 & 8.203 & 6.306 & 7,6 & 6.323 & 66 & 3 & 31 \\
\hline M & 35 & 10.000 & 16.406 & 12.611 & 6,9 & 12.676 & 33 & 11 & 56 \\
\hline M & 40 & 5.000 & 7.430 & 5.706 & 8,5 & 5.723 & 72 & 4 & 24 \\
\hline M & 40 & 10.000 & 14.859 & 11.412 & 7,8 & 11.429 & 37 & 17 & 46 \\
\hline M & 50 & 5.000 & 6.095 & 4.899 & 12,6 & 4.900 & 85 & 4 & 11 \\
\hline M & 50 & 10.000 & 12.190 & 9.797 & 13,9 & 9.816 & 42 & 24 & 34 \\
\hline $\mathrm{F}$ & 35 & 5.000 & 8.203 & 6.306 & 7,5 & 6.329 & 66 & 3 & 31 \\
\hline $\mathrm{F}$ & 35 & 10.000 & 16.406 & 12.611 & 6,7 & 12.659 & 33 & 13 & 54 \\
\hline $\mathrm{F}$ & 40 & 5.000 & 7.430 & 5.706 & 8,3 & 5.717 & 73 & 4 & 23 \\
\hline $\mathrm{F}$ & 40 & 10.000 & 14.859 & 11.412 & 7,5 & 11.489 & 36 & 20 & 44 \\
\hline $\mathrm{F}$ & 50 & 5.000 & 6.095 & 4.899 & 12,1 & 4.903 & 85 & 5 & 10 \\
\hline $\mathrm{F}$ & 50 & 10.000 & 12.190 & 9.797 & 12,9 & 9.828 & 42 & 28 & 30 \\
\hline
\end{tabular}

Fonte: Elaboração dos autores. 


\section{Conclusões}

Este trabalho teve por objetivo analisar os impactos da criação da Funpresp, tendo como objeto os funcionários públicos federais que foram afetados por essa medida. $\mathrm{O}$ arranjo previdenciário vigente após a mudança é denominado de novo regime. Com esse fim, foram empregadas técnicas de matemática atuarial para calcular os valores da aposentadoria nos cenários anterior e posterior à mudança. Os resultados obtidos para o cenário base sugerem que para o servidor médio a mudança é desfavorável, pois este teria uma redução de 17\% (homens) e de $15 \%$ (mulheres) no valor da aposentadoria, caso mudasse para o novo regime. Foram feitos cálculos também para outros perfis de servidores, com diferentes combinações de renda e idade. Os resultados são bastante similares, indicando benefícios no novo regime inferiores aos benefícios oferecidos no antigo regime. As maiores (menores) perdas seriam verificadas para os servidores mais idosos (jovens).

Na sequência foram feitos exercícios adicionais, alterando algumas das premissas inicialmente adotadas, em particular a taxa de juros e a alíquota de contribuição à Funpresp. $\mathrm{O}$ objetivo foi tentar verificar se havia alguma combinação de parâmetros que pudesse eliminar as perdas do optante pelo novo regime. De forma geral, há evidências de que as alíquotas necessárias teriam que ser superiores a 34\% (servidoras mais jovens), alcançando até $74 \%$ (servidores mais idosos). O valor médio encontrado chega próximo a 47\%. No caso das taxas de juros, o padrão de resultados é bastante parecido. Para servidoras mais jovens, uma taxa de juros real de 6,7\% seria suficiente para eliminar perdas em caso de adesão à Funpresp. No caso de servidores mais idosos, o valor alcançaria elevados 13,9\%. Para os perfis adotados, o valor médio encontrado foi de 9,4\%. Cabe lembrar ainda que o esforço contributivo é uma decisão do trabalhador, enquanto a rentabilidade obtida é exógena, dependendo das decisões do gestor dos recursos acumulados e das condições econômicas ao longo de um período de tempo muito elevado.

Analisadas em seu conjunto, essas extensões mostram que seria altamente improvável que a mudança para a Funpresp pudesse não representar perdas para os atuais funcionários públicos. Adicionalmente, o maior peso da parcela capitalizada na composição do benefício coloca o ônus do risco financeiro sobre o servidor, diferentemente do que ocorre com o regime de repartição em vigor anteriormente à criação da Funpresp.

De forma geral, os resultados levam à conclusão de que todos os atuais servidores públicos terão redução em seus benefícios previdenciários caso venham a aderir à Funpresp. Somente condições muito particulares (e altamente improváveis) farão com que sua aposentadoria não seja reduzida. Dessa maneira, há evidências significativas de que a mudança de regras previdenciárias, com a criação da Funpresp, atingirá o objetivo do governo, que é a redução das despesas dos RPPS. Essa redução deverá ser menor no curto prazo, devido à reduzida adesão dos atuais servidores públicos, tendo em vista as perdas evidenciadas neste trabalho. Os resultados mais expressivos somente deverão se materializar no longo prazo, quando os funcionários públicos contratados após a entrada em vigor das medidas começarem a se aposentar. 
Pesquisas futuras podem vir a aprimorar os resultados aqui apresentados de algumas formas. A primeira delas é incorporar um componente estocástico às variáveis relevantes (como taxas de juros e crescimento salarial) de forma a se ter um mapeamento intertemporal mais abrangente dos resultados possíveis. Uma segunda forma é a incorporação de fatores institucionais e políticos, que, embora de grande relevância, fogem ao escopo deste trabalho e da metodologia empregada. Um último comentário deve ser feito, tendo em vista outros trabalhos que venham a abordar o mesmo tema. Usualmente, sistemas previdenciários apresentam um conjunto de regras cuja compreensão não é imediata, nem trivial. Adicionalmente, as decisões ótimas dos trabalhadores envolvem um grande conjunto de variáveis econômicas e demográficas em um horizonte temporal bastante extenso. Dessa maneira, conforme apontam Finseraas e Jakobsson (2013), é possível que os trabalhadores não compreendam adequadamente o desenho do sistema previdenciário e assim venham a tomar decisões subótimas. Esse argumento corrobora os resultados de Liebman e Luttmer (2011), que mostram que medidas de custo muito baixo para aumentar o nível informacional de trabalhadores idosos podem melhorar as decisões tomadas no tocante à oferta de trabalho e à aposentadoria.

Esse parece ser o caso do novo regime, vigente após a criação da Funpresp. Trabalhadores de diferentes perfis terão de tomar em um ambiente de incerteza (particularmente quanto aos rendimentos da parcela capitalizada) uma decisão fundamental ao seu sustento na velhice. Essa decisão de opção por um fundo capitalizado de contribuição definida pode ser influenciada por sua idade e aversão ao risco (Bhandari e Deaves, 2008). Dessa maneira, programas de educação financeira voltados aos servidores em atividade, como os descritos por Clark, Maki e Morrill (2013), podem ter papel muito importante para evitar que decisões do tipo once for all, tão importantes, sejam influenciadas por erros de avaliação.

\section{Referências}

AMARAL, Felipe V. A.; GIAMBIAGI, Fabio; CAETANO, Marcelo A.-R. O fundo previdenciário dos servidores da União: resultados atuariais. Pesquisa e Planejamento Econômico, v. 43, n. 1, p. 119160, 2013.

BARR, Nicholas; DIAMOND, Peter. Reforming pensions: principles and policy choices. Oxford: Oxford University Press, 2008.

BARR, Nicholas; DIAMOND, Peter. The economics of pensions. Oxford Review of Economic Policy, v. 22, n. 1, p. 15-39, 1을. 2006.

BHANDARI, Gokul; DEAVES, Richard. Misinformed and informed asset allocation decisions of self-directed retirement plan members. Journal of Economic Psychology, v. 29, n. 4, p. 473-490, ago. 2008. 
BINSWANGER, Johannes; SCHUNK, Daniel. What is an adequate standard of living during Retirement? Journal of Pension Economics and Finance, v. 11, n. 2, p. 203-222, 2011.

BOVENBERG, Lars; EWIJK, Casper V. Designing the pension system: conceptual framework. In: BOVENBERG, Lars; EWIJK, Casper V.; WESTERHOUT, Ed (Ed.). The future of multi-pillar systems. Cambridge: Cambridge University Press, 2012. p. 142-183.

BOWERS JR., Newton L. et al. Actuarial mathematics. 2. ed. Itasca: Society of Actuaries, 1997.

BROWN, Jeffrey R.; WEISBENNER, Scott J. Why do individuals choose defined contribution plans? Evidence from participants in a large public plan. Journal of Public Economics, v. 116, p. 35-46, 2014.

CALAZANS, Fernando F. et al. A importância da unidade gestora nos regimes próprios de previdência social: análise da situação dos estados e do Distrito Federal. Rev. Adm. Pública, v. 47, n. 2, p. 275-304, 2013.

CLARK, Robert L.; CRAIG, Lee A.; AHMED, Neveen. The evolution of public sector pension plans in the United States. In: MITCHELL, Olivia S.; ANDERSON, Gary (Ed.). The future of public employee retirement systems. Oxford: Oxford University Press, 2009. p. 239-270.

CLARK, Robert L.; MAKI, Jennifer A.; MORRILL, Melinda S. Can simple informational nudges increase employee participation in a 401(k) Plan? NBER Working Paper 19591, 2013.

FELDSTEIN, Martin; LIEBMAN, Jeffrey B. Social security. In: AUERBACH, Alan J.; FELDSTEIN, Martin (Ed.). Handbook of public economics. Amsterdam: North-Holland, 2002. v. 4, p. 2245-2324.

FERREIRA, Gilmar G. Condições atuariais para a construção do fundo previdenciário federal Funpresp. Dissertação (mestrado) - Universidade de São Paulo, São Paulo, 2008.

FINSERAAS, Henning; JAKOBSSON, Niklas. Does information about the pension system affect knowledge and retirement plans? Evidence from a survey experiment. Journal of Pension Economics and Finance, v. 13, n. 3, p. 250-271, 2013.

HOLZMANN, Robert; HINZ, Richard. Old-age income support in the 21st century. Washington, DC: World Bank, 2005.

HUSTEAD, Edwin C.; HUSTEAD, Toni. Federal civilian and military retirement systems. In: MITCHELL, Olivia S.; HUSTEAD, Edwin C. (Ed.). Pensions in the public sector. Philadelphia: University of Pennsylvania Press, 2001. p. 66-104.

KERKHOFF, Toon. Organizational reform and changing ethics in public administration: a case study on 18th century dutch tax collecting. Journal of Public Administration Research and Theory, v. 21, n. 1, p. 117-135, 2009.

LIEBMAN, Jeffrey B.; LUTTMER, Erzo F. P. Would people behave differently if they better understood Social Security? evidence from a field experiment. NBER Working Paper 17287, 2011.

LINDEMAN, David. Issues concerning occupational schemes for civil servants and other public sector workers. OECD Working Paper, 2002. 
MAURER, Raimond; MITCHELL, Olivia S.; ROGALLA, Ralph. Reforming the German civil servant pension plan. In: MITCHELL, Olivia S.; ANDERSON, Gary (Ed.). The future of public employee retirement systems. Oxford: Oxford University Press, 2009. p. 115-142.

MESA-LAGO, Carmelo; MÜLLER, Karina. The politics of pension reform in Latin America. Journal of Latin American Studies, v. 34, n. 3, p. 687-715, 2002.

MPS. Ministério da Previdência Social. Aposentadoria por tempo de contribuição. Disponível em: <http://www.previdencia.gov.br/servicos-ao-cidadao/todos-os-servicos/aposentadoria-por-tempode-contribuicao>. Brasília, 2013. Acesso em: 1ํo maio, 2014.

MPS. Ministério da Previdência Social. Regras para concessão de aposentadoria a servidores vinculados a Regime Próprio de Previdência Social: Resumos esquematizados dos critérios de concessão, cálculo e reajustamento. Brasília, 2009.

MPOG. Ministério do Planejamento, Orçamento e Gestão. Boletim Estatístico de Pessoal e Informações Organizacionais., v. 18, n. 212, dez. 2013.

MITCHELL, Olivia S. et al. Developments in state and local pension plans. In: MITCHELL, Olivia S.; HUSTEAD, Edwin C. (Ed.). Pensions in the public sector. Philadelphia: University of Pennsylvania Press, 2001. p. 11-40.

MORTIMER, John W.; HENDERSON, Linda R. Measuring pension liabilities under Gasb Statement no. 68. Accounting Horizons, v. 28, n. 3, p. 421-454, 2014.

MULLIGAN, Casey B.; SALA-I-MARTIN, Xavier. Social security in theory and practice (I): facts and political theories. NBER Working Paper 7118, 1999a.

MULLIGAN, Casey B.; SALA-I-MARTIN, Xavier. Social security in theory and practice (II): efficiency theories, narrative theories, and implications for reform. NBER Working Paper 7119, 1999b.

NOVY-MARX, Robert; RAUH, Joshua D. Linking benefits to investment performance in US public pension systems. Journal of Public Economics, v. 116, p. 47-61, 2014.

PALACIOS, Robert; WHITEHOUSE, Edward. Civil-service pension schemes around the world. World Bank Social Protection Discussion Paper 0602, 2006.

PALLARES-MIRALLES, Montserrat; ROMERO, Carolina; WHITEHOUSE, Edward. International patterns of pension provision II: a worldwide overview of facts and figures. World Bank Social Protection \& Labor Discussion Paper 1211, 2012.

PARMENTER, Michael M. Theory of interest and life contingencies with pension applications: a problem solving approach. 3. ed. Winsted: Actex, 1999.

PETRICHEV, Konstantin; THORP, Susan. The private value of public pensions. Insurance: Mathematics and Economics, v. 42, n. 3, p. 1138-1145, 2008.

PONDS, Eduard; SEVERINSON, Clara; YERMO, Juan. Funding in public sector pension plans: international evidence: NBER Working Paper 17082, 2011. 
POZZEBON, Silvana. Canadian public sector employee pension plan. In: MITCHELL, Olivia S.; HUSTEAD, Edwin. C. (Ed.). Pensions in the public sector. Philadelphia: University of Pennsylvania Press, 2001. p. 105-116.

RANGEL, Leonardo A.; SABOIA, João L. Criação da previdência complementar dos servidores federais: motivações e implicações na taxa de reposição das futuras aposentadorias. Brasília: Ipea, 2013 (Texto para discussão n. 1847). Disponível em: <www.ipea.gov.br/portal/images/stories/PDFs/ TDs/td_1847.pdf>. Acesso em: 1으 maio 2014.

ROFMAN, Rafael; FAJNZYLBER, Eduardo; HERRERA, German. World Bank Social Protection \& Labor Discussion Paper 0831, 2008.

SAKAMOTO, Junichi. Unifying pension schemes in Japan: toward a single scheme for both civil servants and private employees. In: MITCHELL, Olivia S.; ANDERSON, Gary (Ed.). The future of public employee retirement systems. Oxford: Oxford University Press, 2009. p. 164-186.

SOUZA, André. P.; ZYLBERSTAJN, Hélio; AFONSO, Luís E.; FLORI, Priscilla M. Resultados fiscais da reforma de 2003 no sistema de previdência social brasileiro. Pesquisa e Planejamento Econômico, v. 36, n. 1, p. 1-38, 2006.

Danilo Diogenes Rodrigues é consultor sênior, EY Serviços Atuariais. E-mail: danilodiogenesrodrigues@ gmail.com.

Luís Eduardo Afonso é doutor em economia, livre-docente e professor associado do Departamento de Contabilidade e Atuária da Faculdade de Economia e Administração da Universidade de São Paulo (FEA/ USP). E-mail: lafonso@usp.br. 